\title{
Effect of Various Operational Parameters on Drug Release from a $1 \%$ Hydrocortisone Semisolid Dosage Form Using the Vertical Diffusion Cell Apparatus
}

\author{
Loice Kikwai ${ }^{1}$, Daren Tran², Walter W. Hauck ${ }^{2}$, \\ Vinod P. Shah ${ }^{2}$, and Erika S. Stippler ${ }^{2, *}$ \\ ${ }^{1}$ Food and Drug Administration, Rockville, MD, USA \\ (Note: The opinions expressed here are the author's and do not necessarily reflect the official \\ policies of the US Food and Drug Administration.) \\ ${ }^{2}$ United States Pharmacopeial Convention, Rockville, MD, USA
}

\begin{abstract}
The purpose of this study was to identify operational parameters of the vertical diffusion cell (VDC) apparatus that have an influence on results of drug release testing from semisolid dosage forms, which are one of three types of topically applied products (see USP General Chapter Topical and Transdermal Drug Products—Product Quality Tests $<3>$ ). The VDC apparatus operates using a static diffusion cell, a synthetic membrane, and an appropriate receptor medium. A cream formulation containing $1 \%$ hydrocortisone was used for the current study. The operational parameters investigated were stirring rate, mixing helix, stirring while sampling, medium degassing, membrane wetting with Ethomeen (a surfactant), and membrane wetting time. Stat-Ease design of experiment software was used to create partial factorial experimental designs to evaluate these parameters. The effects of the operational parameters were evaluated using mean drug release rate $\left(\mathrm{slope}, \mu \mathrm{g} / \mathrm{cm}^{2} / \mathrm{min}^{1 / 2}\right)$ and the standard deviation (SD) of six individual release rates for each experimental setup.

Results of the study indicate that one parameter, the presence of Ethomeen for wetting the membrane, had a large and significant effect on both drug release rates and SD. Two parameters, stirring while sampling and mixing helix, had a significant impact on the drug release rate when Ethomeen was not used. Two parameters, medium degassing and stirring while sampling, had significant effects on the variability of the results (SD).

Additionally, instrument-specific parameters (e.g., mixing helix) also contributed significantly to the variability of drug release rates.
\end{abstract}

\section{INTRODUCTION}

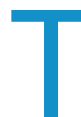

opically applied drug products include ophthalmic, semisolid, and transdermal dosage forms (1). Drug products topically administered via the skin fall into two general categories, those applied for local action (e.g., semisolid dosage forms) and those intended for systemic effects (e.g., transdermal drug products). The drug substance in either category must be released from the carrier before it can contact the epidermal surface and be available for penetration into the stratum corneum and lower layers of the skin. A performance test for topical drug products therefore should be able to measure drug release from the dosage form. Although it is not an indicator of bioavailability, the drug release test should be capable of detecting changes in the finished product drug release characteristics that have the potential to alter the biological performance of the drug in the dosage form. The drug release test for semisolid dosage forms should be reproducible and reliable.

The vertical diffusion cell (VDC) apparatus, which uses a static diffusion cell, a synthetic membrane, and an appropriate receptor medium, has emerged as one of the most

${ }^{*}$ Corresponding author. widely used apparatus for testing the in vitro release of topical dosage forms $(2,3)$. The VDC apparatus is simple to operate and generally yields reliable and reproducible results when employed by properly trained laboratory personnel (4). The objective of the present study was to evaluate the influence of some operational parameters on the release of the drug from the semisolid dosage form. The authors evaluated individual or combined effects of stirring rate, mixing helix, membrane wetting with Ethomeen, membrane wetting time, stirring while sampling, and medium degassing on the release rate of a $1 \%$ hydrocortisone cream formulation using two VDC apparatus, each from a different vendor. The study evaluated the release rate (steady-state flux) and between-cell standard deviation (SD) of release rates of $1 \%$ hydrocortisone cream.

\section{MATERIALS AND METHODS Materials and Reagents}

Reagents used were a current and valid lot of USP Hydrocortisone Reference Standard, Milli-Q water, acetonitrile HPLC grade (Fisher Scientific, Waltham, MA), water HPLC grade, ethanol (Warner Graham, Cockeysville, MD), isopropyl myristate (IPM) (Alfa Aesar, Ward Hill, MA), Ethomeen-12 (AkzoNobel), and Tuffryn 0.45- $\mu \mathrm{m}$ mem- 
Table 1. List of Variables-VDC1 Apparatus

\begin{tabular}{|c|c|c|c|c|}
\hline & Variable & Units & -1 Value & +1 Value \\
\hline $\mathrm{p} a$ & Membrane wetting time & $\min$ & 15 & 30 \\
\hline $1^{b}$ & Rotation speed & rpm & 600 & 800 \\
\hline $\mathrm{p}^{a}$ & Medium degassing & NA & Non-degassed & Degassed \\
\hline $\mathrm{p} a$ & Membrane wetting (Ethomeen) & NA & $100 \%$ IPM $^{c}$ & $15 \% \mathrm{ETMN}^{d}$ in IPM \\
\hline $\mathrm{p} a$ & Stirring while sampling & NA & Stirrer Off & Stirrer On \\
\hline $1^{b}$ & Mixing helix & NA & No Helix & Helix Used \\
\hline \multicolumn{5}{|c|}{$\begin{array}{ll}\text { a } & \text { Procedure-related variable. } \\
\text { b } & \text { Instrument-related variable. } \\
\text { c } & \text { Isopropyl myristate (IPM). } \\
d & \text { Ethomeen (ETMN). }\end{array}$} \\
\hline
\end{tabular}

brane filters (Pall, Ann Arbor, MI). A commercially available cream from one batch of a topical product containing $1 \%$ hydrocortisone was selected for this study.

\section{In Vitro Drug Release Test}

The in vitro release studies were performed on two VDC apparatus termed VDC1 and VDC2. For each apparatus, a set of six diffusion cells with an orifice diameter of $15 \mathrm{~mm}$ and a cell volume of approximately $7 \mathrm{~mL}$ were used. The diffusion cells were kept in the same position during the entire study. The difference between the two apparatus was primarily the design of the diffusion cells. In the VDC1 apparatus, the receptor medium is mixed with a magnetic stirring bar to which a wire helix (mixing helix) is attached. In the VDC2 apparatus, the receptor medium is mixed with a magnetic stirring bar alone. VDC1 can be operated at different stirring rates, whereas VDC2 has one fixed stirring rate.

The in vitro release of the $1 \%$ hydrocortisone from the cream formulation was measured through a $25-\mathrm{mm}$ polysulfone membrane (Tuffryn). For all the baseline tests, the membrane was saturated in a wetting solution for $30 \mathrm{~min}$ before the analyst applied the cream formulation. Excess wetting solution was blotted off the membranes before use. For the perturbation test runs, the membrane was saturated in a wetting solution for either 15 or $30 \mathrm{~min}$ (see Perturbation Settings).
The receptor compartment was filled with a water/ ethanol (70:30) solution and was maintained at $32 \pm 0.5^{\circ} \mathrm{C}$ using a circulating water bath.

Samples were collected from the receptor compartment at $0.5,1,2,3,4$, and $6 \mathrm{~h}$. After sampling, an identical volume of fresh medium maintained at $32 \pm 0.5^{\circ} \mathrm{C}$ was introduced into the cell.

Because of slight differences in the design of the VDC apparatus, the baseline experiments were conducted according to each apparatus' specific operating instructions. For each of the two VDC apparatus, the baseline runs consisted of a set of three individual tests.

\section{Perturbation Settings}

The operational and procedural variables chosen in this study were stirring rate, mixing helix, membrane wetting with Ethomeen, membrane wetting time, stirring while sampling, and medium degassing.

\section{Stirring Rate (Rotation Speed)}

This parameter was evaluated only in the VDC1 apparatus. The speed was set at either 800 or $600 \mathrm{rpm}$. The speed was $600 \mathrm{rpm}$ for all VDC2 runs.

\section{Mixing Helix}

A stirring magnet was used for all experiments. The tests were conducted with and without a mixing helix in both

Table 2. List of Variables-VDC2 Apparatus

\begin{tabular}{|c|c|c|c|c|}
\hline & Variable & Units & -1 Value & +1 Value \\
\hline $\mathrm{P}^{a}$ & Membrane wetting time & $\min$ & 15 & 30 \\
\hline $\mathrm{P}^{a}$ & Medium degassing & NA & Non-degassed & Degassed \\
\hline $\mathrm{P}^{a}$ & Membrane wetting (Ethomeen) & NA & $100 \%$ IPM $^{c}$ & $15 \% \mathrm{ETMN}^{d}$ in IPM \\
\hline $\mathrm{p}^{a}$ & Stirring while sampling & NA & Stirrer Off & Stirrer On \\
\hline $\mathrm{I}^{b}$ & Mixing helix & NA & No Helix & Helix Used \\
\hline
\end{tabular}


Table 3. Experimental Design and Results_VDC1 Apparatus

\begin{tabular}{|c|c|c|c|c|c|c|c|c|}
\hline Run & $\begin{array}{c}\text { Membrane } \\
\text { Wetting Time (A) } \\
\text { min }\end{array}$ & $\begin{array}{l}\text { Rotation Speed } \\
\text { (B) rpm }\end{array}$ & $\begin{array}{c}\text { Medium } \\
\text { Degassing (C) }\end{array}$ & $\begin{array}{c}\text { Membrane } \\
\text { Wetting with } \\
\text { Ethomeen (D) }\end{array}$ & $\begin{array}{l}\text { Stirring while } \\
\text { Sampling (E) }\end{array}$ & $\begin{array}{c}\text { Mixing Helix } \\
\text { (F) }\end{array}$ & $\begin{array}{l}\text { Mean Slope } \\
\mu \mathrm{g} / \mathrm{cm}^{2} / \mathrm{min}^{1 / 2}\end{array}$ & SD \\
\hline B_1 & & & & & & & 22.7 & 1.0 \\
\hline B_2 & 30 & 800 & Yes & Yes & No & Yes & 22.7 & 1.3 \\
\hline B_3 & & & & & & & 22.2 & 1.5 \\
\hline 1 & 15 & 800 & No & No & Yes & No & 15.4 & 0.3 \\
\hline 2 & 15 & 800 & Yes & Yes & Yes & No & 20.4 & 2.0 \\
\hline 3 & 30 & 600 & No & Yes & No & No & 20.8 & 1.5 \\
\hline 4 & 15 & 800 & No & No & No & Yes & 17.5 & 1.0 \\
\hline 5 & 30 & 800 & No & Yes & Yes & No & 19.7 & 1.3 \\
\hline 6 & 15 & 600 & Yes & Yes & No & No & 19.0 & 0.9 \\
\hline 7 & 30 & 800 & No & No & No & No & 17.0 & 0.8 \\
\hline 8 & 15 & 600 & No & Yes & Yes & No & 19.5 & 1.2 \\
\hline 9 & 15 & 800 & Yes & No & No & No & 15.8 & 0.9 \\
\hline 10 & 15 & 600 & Yes & No & Yes & No & 15.4 & 0.9 \\
\hline 11 & 30 & 800 & No & No & Yes & Yes & 15.8 & 0.7 \\
\hline 12 & 30 & 800 & Yes & Yes & No & No & 17.3 & 1.0 \\
\hline 13 & 30 & 600 & No & No & Yes & No & 16.0 & 0.5 \\
\hline 14 & 30 & 600 & No & No & No & Yes & 17.5 & 0.9 \\
\hline 15 & 30 & 800 & No & Yes & No & Yes & 20.6 & 0.7 \\
\hline 16 & 15 & 600 & Yes & Yes & Yes & Yes & 18.8 & 0.8 \\
\hline 17 & 30 & 600 & Yes & No & Yes & Yes & 16.1 & 0.7 \\
\hline 18 & 15 & 600 & No & No & No & No & 16.8 & 0.5 \\
\hline 19 & 30 & 600 & No & Yes & Yes & Yes & 20.2 & 1.4 \\
\hline 20 & 15 & 600 & No & Yes & No & Yes & 20.8 & 1.0 \\
\hline 21 & 15 & 600 & Yes & No & No & Yes & 17.0 & 0.7 \\
\hline 22 & 15 & 800 & Yes & Yes & No & Yes & 20.9 & 1.7 \\
\hline 23 & 15 & 800 & No & Yes & No & No & 19.9 & 1.2 \\
\hline 24 & 15 & 800 & Yes & No & Yes & Yes & 15.9 & 0.6 \\
\hline 25 & 30 & 600 & Yes & Yes & Yes & No & 20.1 & 1.5 \\
\hline 26 & 30 & 800 & Yes & Yes & Yes & Yes & 20.1 & 2.7 \\
\hline 27 & 30 & 800 & Yes & No & Yes & No & 15.9 & 0.7 \\
\hline 28 & 30 & 600 & Yes & Yes & No & Yes & 22.6 & 1.5 \\
\hline 29 & 15 & 800 & No & Yes & Yes & Yes & 21.0 & 0.9 \\
\hline 30 & 30 & 800 & Yes & No & No & Yes & 17.2 & 1.1 \\
\hline 31 & 15 & 600 & No & No & Yes & Yes & 16.1 & 0.4 \\
\hline 32 & 30 & 600 & Yes & No & No & No & 17.0 & 1.1 \\
\hline
\end{tabular}




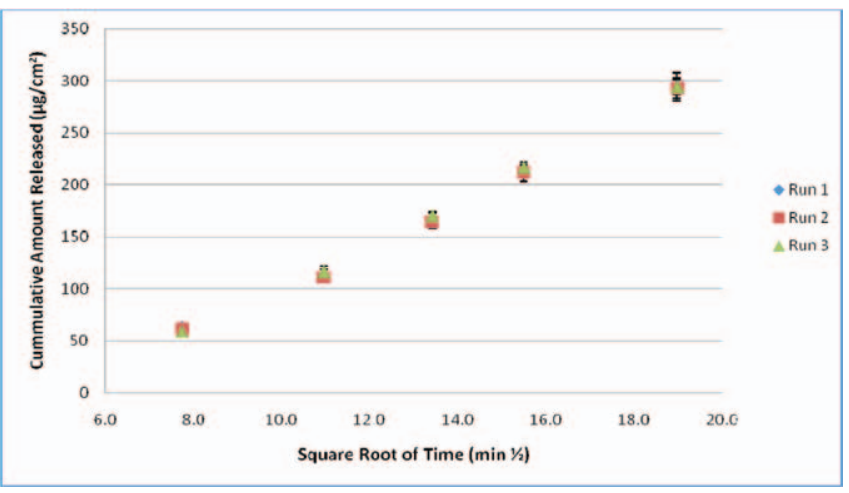

Figure 1. In vitro release of $1 \%$ hydrocortisone cream baseline runs on VDC1 apparatus.

apparatus. Because VDC2 usually does not require the use of a mixing helix, the one from VDC1 was used as needed.

\section{Membrane Wetting with Ethomeen}

Either a $15 \%$ preparation of Ethomeen (a surfactant) in isopropyl myristate (IPM) or $100 \%$ IPM was used as the membrane wetting solution.

\section{Membrane Wetting Time}

Membranes were wetted for either 15 or $30 \mathrm{~min}$.

\section{Stirring While Sampling}

The sampling process was accomplished with the stirring device left on or turned off. The device was turned off $30 \mathrm{~s}$ before sampling.

\section{Medium Degassing}

Degassed or nondegassed medium was used for each experiment. The medium was degassed by vacuum filtration at room temperature, and then the medium was kept under vacuum for an additional $2 \mathrm{~min}$.

\section{HPLC Conditions}

Hydrocortisone was analyzed using a validated HPLC method with UV detection at $242 \mathrm{~nm}$. The HPLC method consisted of a $5-\mu \mathrm{m}, 50 \times 3.9 \mathrm{~mm}$ Symmetry $\mathrm{C} 18$ column (Waters) operated at room temperature, an 80:20 water/ acetonitrile mixture as the mobile phase at a flow rate of 1.0 $\mathrm{mL} / \mathrm{min}$, and a $10-\mu \mathrm{L}$ injection volume. For each HPLC run, the system suitability was checked and was determined to comply with the USP requirements stated in General Chapter Chromatography <621 > (data not provided).

\section{Experimental Design}

A design-of-experiment (DoE) statistical software package (Design-Expert Version 7.0.2, Stat-Ease, Inc., Minneapolis, MN) was employed to design two partial factorial experiments that satisfied a condition for aliasing. Aliasing alludes to effects confounded with other effects. The condition for aliasing in the study was that

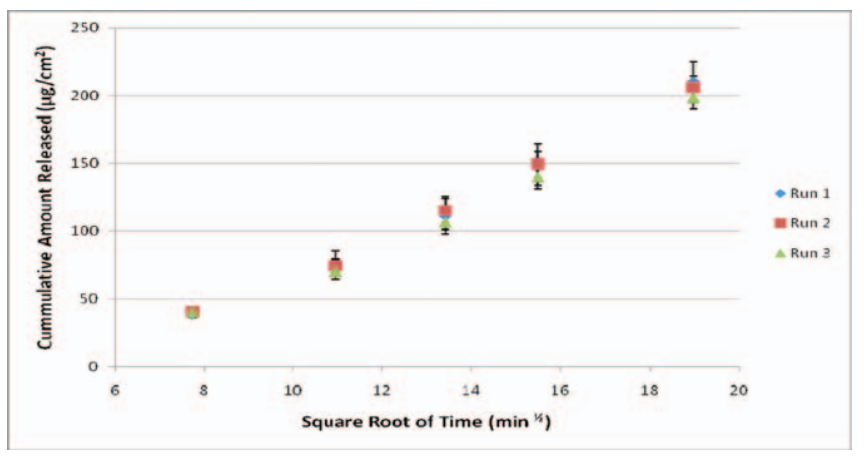

Figure 2. In vitro release of $1 \%$ hydrocortisone cream baseline runs on VDC2 apparatus.

main effects not be aliased with any other effect and that two-way interactions be aliased at most with higher-order interactions. The operational and procedural variables included in the DoE study are summarized in Tables 1 and 2. For the VDC1 apparatus, the design $\left(2^{6-1}\right.$ Resolution $\left.\mathrm{VI}\right)$ consisted of 32 experiments, and for the VDC2 apparatus, the design ( $2^{5-1}$ Resolution V) consisted of 16 experiments with replication, resulting in 32 total runs. The order of experiments and the variables were randomized by the software (Tables 3 and 4), but because of shared equipment components (mixing helix), the exact order of runs was not followed precisely.

\section{Statistical Analysis}

The DoE software was used to analyze the data. Two responses were recorded and analyzed: the average release rate $\left(\mathrm{mg} / \mathrm{cm}^{2} / \mathrm{min}^{1 / 2}\right)$ and the standard deviation of the six slopes for each test setup. The data for the average release rate were not transformed, but the data analysis for the standard deviation used a base 10 log transformation. We forced all main effects to be part of our final models so we could evaluate all effects. In addition, we added interactions (combination effects) if their importance as measured by percent sum of squares was comparable to that of the more important main effects. Pareto charts are used to illustrate the importance of the variables. These charts show significance levels with Bonferroni correction and without adjustment for multiple testing. We emphasize results adjusted for multiple testing. After variables were selected, an analysis of variance (ANOVA) was performed to quantify the contribution of each significant variable.

\section{RESULTS}

The average cumulative amount of hydrocortisone released per unit surface area $\left(\mathrm{mg} / \mathrm{cm}^{2}\right)$ was plotted against the square root of time. Plots of baseline experiments are shown in Figures 1 and 2 for each apparatus. The slope that represents the release rate (i.e., steady-state flux, $\mathrm{mg} / \mathrm{cm}^{2} / \mathrm{min}^{1 / 2}$ ) was calculated by linear regression, and the values (average of six cells 
Table 4. Experimental Design and Results-VDC2 Apparatus

\begin{tabular}{|c|c|c|c|c|c|c|c|}
\hline Run & $\begin{array}{l}\text { Membrane Wetting } \\
\text { Time (A) min }\end{array}$ & $\begin{array}{c}\text { Medium } \\
\text { Degassing (B) }\end{array}$ & $\begin{array}{c}\text { Membrane Wetting with } \\
\text { Ethomeen (C) }\end{array}$ & $\begin{array}{l}\text { Stirring while } \\
\text { Sampling (D) }\end{array}$ & $\begin{array}{l}\text { Mixing Helix } \\
\text { (E) }\end{array}$ & $\begin{array}{l}\text { Mean Slope } \\
\mu \mathrm{g} / \mathrm{cm}^{2} / \mathrm{min}^{1 / 2}\end{array}$ & SD \\
\hline B_1 & & & & & & 17.1 & 0.7 \\
\hline B_2 & 30 & Yes & Yes & No & No & 16.4 & 0.5 \\
\hline B_3 & & & & & & 16.1 & 1.2 \\
\hline 1 & 30 & Yes & Yes & Yes & Yes & 17.3 & 0.4 \\
\hline 2 & 15 & Yes & No & Yes & Yes & 12.7 & 0.4 \\
\hline 3 & 15 & No & Yes & No & No & 17.1 & 1.5 \\
\hline 4 & 30 & Yes & No & No & Yes & 12.2 & 0.4 \\
\hline 5 & 30 & No & Yes & Yes & No & 16.7 & 1.3 \\
\hline 6 & 15 & Yes & Yes & Yes & No & 14.8 & 0.8 \\
\hline 7 & 30 & No & Yes & No & Yes & 14.3 & 1.0 \\
\hline 8 & 30 & No & No & No & No & 10.9 & 0.3 \\
\hline 9 & 15 & No & Yes & Yes & Yes & 14.2 & 1.0 \\
\hline 10 & 15 & No & No & Yes & No & 11.5 & 0.5 \\
\hline 11 & 30 & No & No & Yes & Yes & 11.4 & 0.7 \\
\hline 12 & 30 & Yes & No & Yes & No & 11.5 & 0.3 \\
\hline 13 & 15 & Yes & No & No & No & 11.7 & 0.4 \\
\hline 14 & 15 & Yes & No & No & No & 11.9 & 0.3 \\
\hline 15 & 30 & No & Yes & Yes & No & 15.1 & 1.1 \\
\hline 16 & 15 & No & No & Yes & No & 12.5 & 0.6 \\
\hline 17 & 15 & No & No & No & Yes & 12.0 & 0.7 \\
\hline 18 & 15 & Yes & Yes & Yes & No & 15.9 & 0.7 \\
\hline 19 & 30 & No & No & No & No & 12.4 & 0.5 \\
\hline 20 & 30 & Yes & No & No & Yes & 13.0 & 0.3 \\
\hline 21 & 15 & No & Yes & Yes & Yes & 16.8 & 1.1 \\
\hline 22 & 15 & No & No & No & Yes & 13.2 & 0.6 \\
\hline 23 & 30 & Yes & Yes & No & No & 16.6 & 1.8 \\
\hline 24 & 15 & No & Yes & No & No & 17.2 & 0.6 \\
\hline 25 & 15 & Yes & Yes & No & Yes & 16.4 & 1.2 \\
\hline 26 & 30 & No & No & Yes & Yes & 13.5 & 0.7 \\
\hline 27 & 15 & Yes & Yes & No & Yes & 17.0 & 1.2 \\
\hline 28 & 30 & Yes & Yes & No & No & 16.2 & 0.7 \\
\hline 29 & 30 & Yes & No & Yes & No & 13.2 & 0.5 \\
\hline 30 & 30 & Yes & Yes & Yes & Yes & 16.7 & 0.8 \\
\hline 31 & 30 & No & Yes & No & Yes & 18.0 & 1.3 \\
\hline 32 & 15 & Yes & No & Yes & Yes & 13.1 & 0.5 \\
\hline
\end{tabular}


Design-Experte Sonware
Mean Slope A: Membrane Wetting Time B: Rotation Speed
C: Medium Degassing

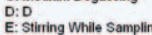
F: Miking-Hellix in Postive Effects

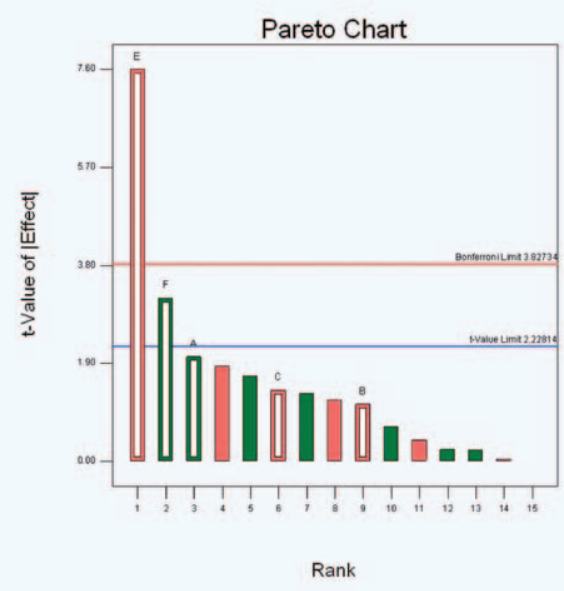

Figure 3. VDC1 apparatus Pareto chart for the analysis of average release rate $\left(\mathrm{mg} / \mathrm{cm}^{2} / \mathrm{min}^{1 / 2}\right.$ )—no Ethomeen (i.e., 100\% IPM). The two significant variables were $(E)$ stirring while sampling and $(F)$ mixing helix.

for each run) are summarized in Tables 3 and 4. A lag time was observed at the 1-h time point, so the data from $1 \mathrm{~h}$ were omitted when we calculated the steadystate flux. The cumulative amount of drug released was linear after the 1-h time point and was proportional to the square root of time. Hence, release of hydrocortisone from the cream formulation follows the Higuchi diffusion-controlled model (5). Additional studies are planned to further evaluate the occurrence of lag time and potential membrane binding.

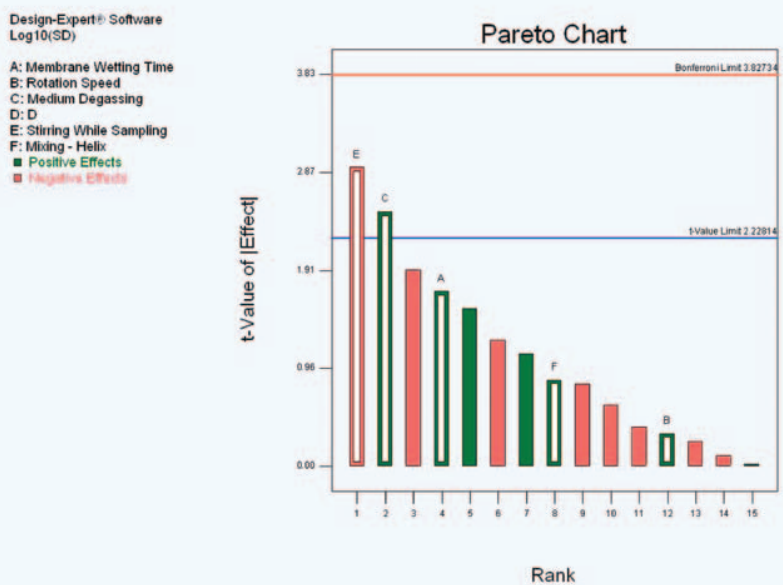

Figure 4. VDC1 apparatus Pareto chart for the analysis of standard deviation-no Ethomeen (i.e., 100\% IPM). The two significant variables were (E) stirring while sampling and $(C)$ medium degassing.

Tables 5 and 6 show the influence of the experimental variables on the drug release results of hydrocortisone cream in terms of the average $(n=6)$ release rate $(\mathrm{mg} /$ $\mathrm{cm}^{2} / \mathrm{min}^{1 / 2}$ ) and standard deviation data for the experiments performed using VDC1 and VDC2. The effect is the change in the response as the factor changes from its low level (i.e., -1 Value as indicated in Tables 1 and 2) to its high level (i.e., +1 Value as indicated in Tables 1 and 2).

As is evident in Tables 5 and 6 , the use of Ethomeen has an overwhelming effect relative to all other factors studied

Table 5. Effects for In Vitro Release Rate (Average release rate- $\mu \mathrm{g} / \mathrm{cm}^{2} / \mathrm{min}^{1 / 2}$ )

\begin{tabular}{|c|c|c|c|c|}
\hline \multirow[b]{2}{*}{ Variable } & \multicolumn{2}{|c|}{ With Ethomeen } & \multicolumn{2}{|c|}{ Without Ethomeen } \\
\hline & Effect $^{a}$ & $\%$ Contribution $^{b}$ & Effect $^{a}$ & $\%$ Contribution \\
\hline \multicolumn{5}{|l|}{ VDC1 Apparatus } \\
\hline A. Membrane Wetting Time & 0.2 & 0.3 & 0.3 & 4.8 \\
\hline B. Rotation Speed & -0.2 & 0.2 & -0.2 & 1.4 \\
\hline C. Medium Degassing & -0.3 & 0.6 & -0.2 & 2.2 \\
\hline D. Membrane Wetting with Ethomeen & $3.7^{c}$ & 79.4 & - & - \\
\hline E. Stirring while Sampling & -0.7 & 2.9 & $-1.2^{c}$ & 68.0 \\
\hline F. Mixing helix & 0.8 & 3.5 & $0.5^{d}$ & 11.8 \\
\hline \multicolumn{5}{|l|}{ VDC2 Apparatus } \\
\hline A. Membrane Wetting Time & 0.0 & 0.0 & -0.1 & 0.4 \\
\hline B. Medium Degassing & 0.2 & 0.2 & 0.2 & 2.6 \\
\hline C. Membrane Wetting with Ethomeen & $4.0^{c}$ & 81.7 & - & - \\
\hline D. Stirring while Sampling & -0.2 & 0.2 & 0.3 & 3.0 \\
\hline E. Mixing helix & 0.4 & 0.9 & 0.7 & 19.9 \\
\hline $\begin{array}{l}\text { a The effect size is the difference between t } \\
\text { b \% contribution does not add to } 100 \% \text { bec } \\
\text { c Statistically significant at the } 5 \% \text { level aft } \\
\text { d Statistically significant at the } 5 \% \text { level be }\end{array}$ & $\begin{array}{l}\text { he }+1 \text { se } \\
\text { hown. }\end{array}$ & Is that at the -1 sett & & \\
\hline
\end{tabular}


Table 6. Effects for Standard Deviation of In Vitro Release Rate

\begin{tabular}{|c|c|c|c|c|}
\hline \multirow[b]{2}{*}{ Variable } & \multicolumn{2}{|c|}{ With Ethomeen } & \multicolumn{2}{|c|}{ Without Ethomeen } \\
\hline & Effect $^{a}$ & $\%$ Contribution $^{b}$ & Effect $^{a}$ & $\%$ Contribution \\
\hline \multicolumn{5}{|l|}{ VDC1 Apparatus } \\
\hline A. Membrane Wetting Time & 20.2 & 4.3 & 23.9 & 10.3 \\
\hline B. Rotation Speed & 7.4 & 0.7 & 4.0 & 0.4 \\
\hline C. Medium Degassing & 28.8 & 8.7 & $38.0^{d}$ & 21.8 \\
\hline D. Membrane Wetting with Ethomeen & $82.0^{c}$ & 43.5 & - & - \\
\hline E. Stirring while Sampling & -7.7 & 0.8 & $-30.8^{d}$ & 30.0 \\
\hline F. Mixing helix & 3.3 & 0.1 & 11.2 & 2.5 \\
\hline \multicolumn{5}{|l|}{ VDC2 Apparatus } \\
\hline A. Membrane Wetting Time & -6.7 & 0.5 & -8.8 & 2.9 \\
\hline B. Medium Degassing & -24.1 & 8.3 & $-29.2^{c}$ & 39.2 \\
\hline C. Membrane Wetting with Ethomeen & $104.2^{c}$ & 54.4 & - & - \\
\hline D. Stirring while Sampling & -3.2 & 0.1 & 18.6 & 9.8 \\
\hline E. Mixing helix & 9.1 & 0.8 & $25.3^{d}$ & 17.3 \\
\hline $\begin{array}{l}\text { a The effect size is the difference between t } \\
\text { positive effects correspond to lower varic } \\
\text { b Percent contribution does not add to } 100 \\
\text { c Statistically significant at the } 5 \% \text { level aft } \\
\text { d Statistically significant at the } 5 \% \text { level be }\end{array}$ & $\begin{array}{l}\text { setting } m \\
\text { d negativ } \\
\text { shown. } \\
\text { ferroniad }\end{array}$ & $\begin{array}{l}\text { It the }-1 \text { setting as } \\
\text { orrespond to lower }\end{array}$ & $\begin{array}{l}\text { e of thes } \\
\text { the }+1 \mathrm{~s}\end{array}$ & e-1 setting. That is, \\
\hline
\end{tabular}

and shows highly significant effects on both the average and standard deviation of release rate. On average, with Ethomeen the release rate is about 20\% higher, but the standard deviation is about doubled, corresponding to about a two-thirds increase in the coefficient of variation.

As a result of the effect of membrane wetting with Ethomeen, the data were reanalyzed by excluding the runs that used Ethomeen. For all the remaining runs, the membrane was wetted in $100 \%$ IPM solution.

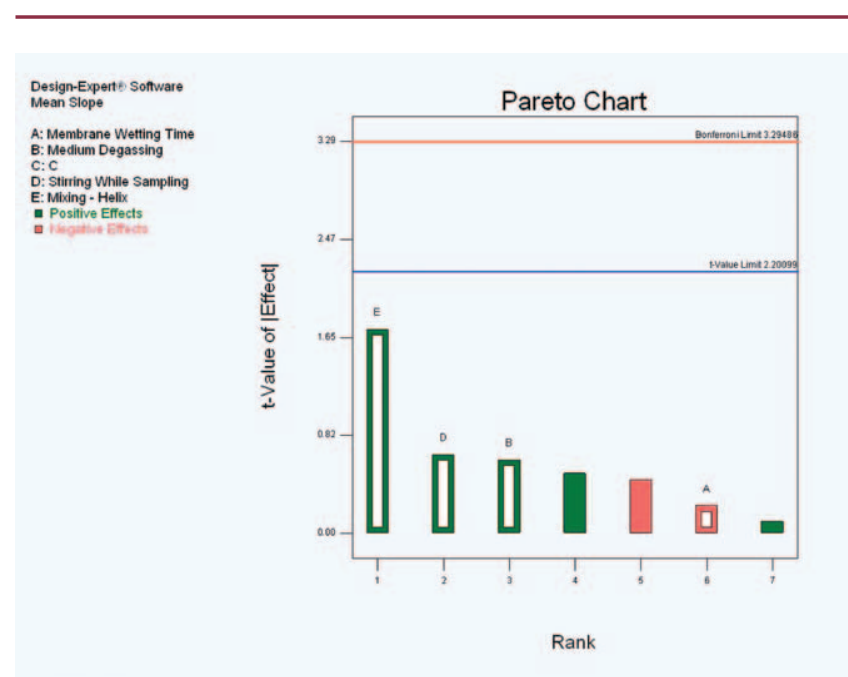

Figure 5. VDC2 apparatus Pareto chart for the analysis of average release rate $\left(\mathrm{mg} / \mathrm{cm}^{2} / \mathrm{min}^{1 / 2}\right)$ - no Ethomeen (i.e., 100\% IPM). None of the variables had a significant effect on the mean slope $\left(\mathrm{mg} / \mathrm{cm}^{2} / \mathrm{min}^{1 / 2}\right)$ results.
For the tests in VDC1, stirring while sampling (E) had a statistically significant contribution, and stirring led to a smaller average release rate (Figure 3 and Table 5). Use of the mixing helix (F) also had a fairly large effect, but statistical significance did not reach the Bonferroni limit. From Figure 4 and Table 6 for the standard deviation results, we see that no factor reached the Bonferroni limit in this reduced data set. The two most important variables were stirring while sampling (E) and medium degassing (C).
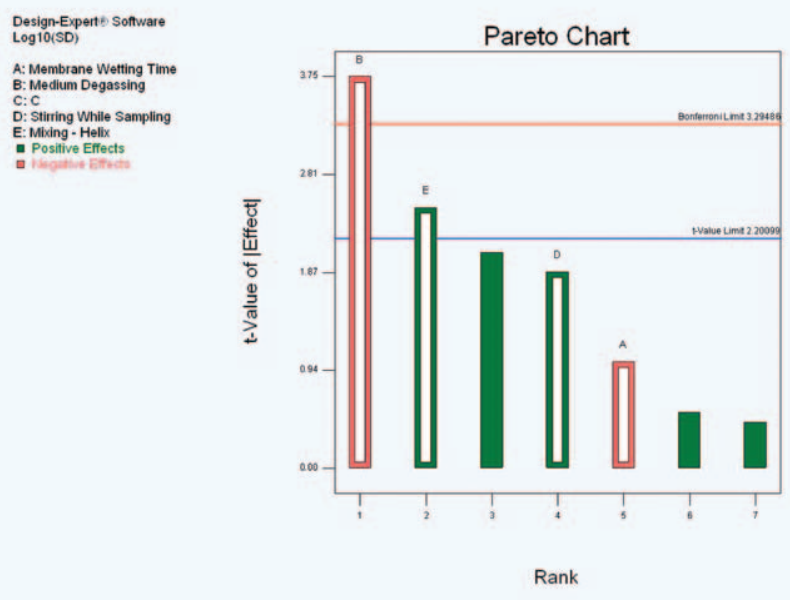

Figure 6. VDC2 apparatus Pareto chart for the analysis of standard deviation-no Ethomeen (i.e., 100\% IPM). Variables that have significant effect on the standard deviation are (B) medium degassing and (E) mixing helix. 
Figures 5 and 6 show Pareto charts for the average release rate $\left(\mathrm{mg} / \mathrm{cm}^{2} / \mathrm{min}^{1 / 2}\right)$ and standard deviation data for the runs performed in VDC2 without Ethomeen as a variable. Variables with red bars represent a negative effect (decrease) from the low level ( -1 Value) to the high level (+1 Value). Green bars represent a positive effect (increase). None of the variables had a significant effect on the average release rate results (Figure 5). Data in Figure 6 show that variables that had a significant effect on the standard deviation are medium degassing $(\mathrm{B})$ and mixing helix $(\mathrm{E})$, although the latter did not reach the Bonferroni limit.

\section{DISCUSSION}

We used two similar VDC apparatus to evaluate the individual or combined effects of stirring rate, mixing helix, membrane wetting with Ethomeen, membrane wetting time, stirring while sampling, and medium degassing on the in vitro release rate of a $1 \%$ hydrocortisone cream formulation. We found large effects for both method-related variables (e.g., membrane wetting with Ethomeen, stirring while sampling, and degassing) and instrument-related variables (e.g., mixing helix).

For both apparatus, wetting the membrane with Ethomeen had a large and statistically significant effect on the in vitro release rate and standard deviation of the cream formulation and, in particular, substantially increased the variability of results.

For VDC1 experiments that did not utilize Ethomeen, we found that stirring while sampling and mixing helix are variables that influenced the in vitro release rate of the hydrocortisone cream, although the effect of the mixing helix did not reach the Bonferroni limit. These studies used only half the runs and have less statistical power than the experiments as originally designed.

In the case of the tests performed in the VDC2 apparatus for experiments that did not use Ethomeen, none of the variables investigated had a statistically significant influence on the in vitro release rate of the hydrocortisone cream. However, degassing and use of a mixing helix contributed significantly to the variability of the results (SD). The effect of degassing on variability was different in the two apparatus, decreasing variability in VDC2 and increasing it in VDC1.

\section{CONCLUSION}

A DoE approach was used to identify which operational variables have a significant effect on the drug release rate in two VDCs, specifically steady-state flux $\left(\mathrm{mg} / \mathrm{cm}^{2}\right.$ / $\left.\mathrm{min}^{1 / 2}\right)$, and on the variability of a hydrocortisone cream formulation. Additionally, differences in the sensitivity of different VCD apparatus to operational parameters could be identified.

The use of Ethomeen for membrane wetting has such a substantial impact on results that use in the drug release test should be discontinued. Further studies are needed to evaluate the utility of IPM as a membrane wetting solution.

\section{ACKNOWLEDGMENT}

The authors thank Stefan Schuber, Ph.D., ELS, of USP for editorial assistance.

\section{REFERENCES}

1. Topical and Transdermal Drug Products-Product Quality Tests $<3>$. In United States Pharmacopeia and National Formulary USP 35-NF 30; The United States Pharmacopeial Convention, Inc.: Rockville, MD, 2012; pp 37-41.

2. Flynn, G. L.; Shah, V. P.; Tenjarla, S. N.; Corbo, M.; DeMagistris, D.; Feldman, T. G.; Franz, T. J.; Miran, D. R.; Pearce, D. M.; Sequeira, J. A.; Swarbrick, J.; Wang, J. C.; Yacobi, A.; Zatz, J. L. Assessment of value and applications of in vitro testing of topical dermatological drug products. Pharm. Res. 1999, 16 (9), 1325-1330.

3. Shah, V. P.; Elkins, J. S.; Williams, R. L. Evaluation of the Test System Used for In Vitro Release of Drugs for Topical Dermatological Drug Products. Pharm. Dev. Technol. 1999, 4 (3), 377-385.

4. Shah, V. P.; Shaw, S. W.; Norton, D. D.; Elkins, J.; Hanson, R. In Vitro Release: Collaborative Study Using the Vertical Diffusion Cell. Pharm. Forum. 2006, 32 (5), 1590-1597.

5. Higuchi, W. I. Analysis of data on the medicament release from ointments. J. Pharm. Sci. 1962, 51 (8), 802-804. 